\title{
Implication of Active Learning Techniques in Learning Thermodynamics Energy Conversion using BLOSSOMS Thermodynamics Energy Conversion Video towards Engineering Undergraduates Performance
}

\author{
https://doi.org/10.3991/ijet.v14i24.12097 \\ Wan Akmal Izzati Wan Mohd Zawawi $\left.{ }^{(}\right)$, Khairiyah Mohd Yusof, Nur Fazirah Ju- \\ mari, Nor Azlinda Azmi, Tengku Nur Zulaikha Tengku Malim Busu \\ Universiti Teknologi Malaysia, Johor, Malaysia. \\ wa.izzati@utm.my
}

\begin{abstract}
Utilization of BLOSSOMS Thermodynamics Energy Conversion video to properly incorporate active learning techniques had been shown to increase the students' performance in learning introductory Thermodynamics topics. In this study, the effectiveness of using BLOSSOMS Thermodynamics Energy Conversion video towards students' learning in a classroom when adopted by lecturers who is not trained in active learning is investigated. Two groups of undergraduate engineering students from a control class and a treatment class were involved in this study. The students from the treatment class were taught by a lecturer using the BLOSSOMS Thermodynamics Energy Conversion video, while the students from control class underwent conventional lecture style. The students were given pre and post inventory tests and their results were analysed using SPSS. It was found that BLOSSOMS Thermodynamics Energy Conversion video without the proper implementation of active learning technique does not have a significant effect on the individual learning gain of the inventory test among students. The utilization of the video could be more effective if the instructor is well-trained in active learning techniques.
\end{abstract}

Keywords - Thermodynamics, energy conversion, video learning, active learning, How People Learn framework.

\section{Introduction}

\subsection{Background of study}

Thermodynamics is known as one of the toughest fundamental subjects in engineering courses. Mastering the topic requires the students to understand the abstract concepts, long equations, and tedious processes [1 - 4]. Various computer or multimedia applications have been developed to address the difficulty in learning thermodynamics [1]. They are preferred as they are more flexible where illustrative anima- 
tions, simulations, or further explanation with visualizations can be encompassed that could benefit in assisting students to develop their thinking.

To develop students' thinking in the 21 st Century, students must be educated using the student-centered approach [5]. Active learning is one of the student-centred learning approaches that engages students in learning activities rather than passively listening to lectures. The activities include discussing, reading, higher-level thinking, reflecting, etc. Active learning has been shown to enhance learning among students [5, 6]. In fact, active learning can be twice as effective as lecturing if it is properly implemented [8]. Thus, the integration of the right implementation of active learning and technology could be effective in students learning, especially for tough courses.

However, not all lecturers have the skill to conduct active learning. Even after undergoing training, some lecturers have difficulties to change and accept active learning. To assist lecturers to teach Thermodynamics using active learning, BLOSSOMS Thermodynamics Energy Conversion was designed [9]. BLOSSOMS or Blended Learning Open Source Science and Math Studies, is an initiative of LINC (Learning International Networks Consortium) of Massachusetts Institute of Technology (MIT), a global consortium of educators interested in using distance and e-learning technologies to increase access to quality education worldwide. It is an "Open Educational Resource," a web-based collection of materials offered freely and openly for re-use in teaching, learning and research that supports and promotes blended learning and prepare a variety of teaching model especially for math and science subjects [10].

BLOSSOMS Thermodynamics Energy Conversion in Generating Electricity video was designed as an approach for assisting the teaching and learning of thermodynamics. It was designed based on the How People Learn (HPL) framework, which gave 4 overlapping criteria to have an effective learning environment, i.e. knowledge centered, learner centered, assessment centered, and community centered [11]. The video lesson was divided into four segments, which are Segment 1: Concept of energy; Segment 2: Process of energy conversion; Segment 3: Site visit; and the last segment is Teacher's guide, which is arranged for assisting lecturers in using the video in class. Figure 1(a) until Figure 1(d) shows the snapshots taken from the video, which encompasses explanation, animation, and application. The segmentation allows the class lecturer to conduct activities through active learning exercise after each segment.

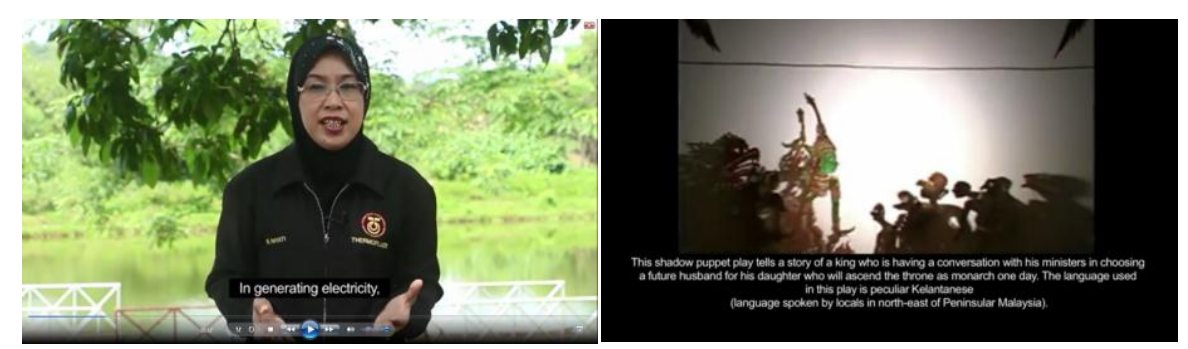

Fig. 1. (a) An instructor guiding the viewers throughout the video
Fig. 1. (b) A shadow play performance shown at the beginning of the video 


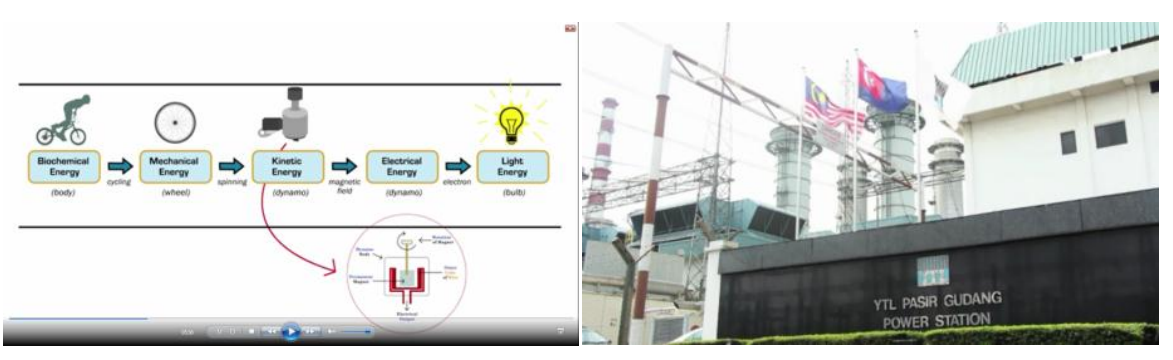

Fig. 1. (c) Animation of processes of energy

Fig. 1. (d) Visit to power station conversion

A previous study [9] on the use of the video in a Thermodynamics class has shown that students who had learned through a class conducted using the BLOSSOMS Thermodynamics video made significant improvement compared to students who have taught using conventional lectures. In the study, both lecturers in the control and treatment classes are good lecturers for the course. The lecturer who taught using the BLOSSOMS video had received training on how to conduct active learning were thus comfortable to implement the approach in class. This shows that the BLOSSOMS video with active learning activities properly implemented was able to effectively enhance students' understanding in the Introduction to Thermodynamics topic $[9,12]$. The scores incremental of Thermodynamics Energy Conversion inventory test between pre-test and post-test among students in the treatment class who used the Energy Conversion BLOSSOMS video gave significant result. The percentage of learning gains of treatment class was higher than that in the control class, in which conventional lecture style was utilized [9]. Thus, the blended learning approach with the implementation of active learning could increase students' performance.

\subsection{Research objectives}

Since the BLOSSOMS Thermodynamics video have been shown to be effective in helping students' understanding of introductory Thermodynamics, further investigation is needed to see if it can be used to assist lecturers to conduct Thermodynamics course even though the lecturer has not been trained in active learning. Therefore, the purpose of the paper is to study the effectiveness of using the video in a first year Thermodynamics course taught by a lecturer who have not been trained in conducting active learning. The research questions are:

1. What are the students' pre-test and post-test performance in the Thermodynamics Energy Conversion topic utilizing the BLOSSOMS video and without utilizing BLOSSOMS video?

2. To what extent is the effectiveness of the BLOSSOMS video when adopted by lecturers who have not been trained in active learning? 


\section{$2 \quad$ Method}

The sample involved a total of 63 first year engineering students taking Thermodynamics course from two classes in a public university in Malaysia, where one class was the treatment class and another class was the control class. From the treatment class students, 24 students scored 3.5-4.0, and 5 students scored 3.0-3.49 in their last semester CPA. Meanwhile, from the control class students, 16 students scored 3.54.0, 9 students scored 3.0-3.49, 3 scored 2.0-2.99 in their last semester CGPA, and 6 students who did not indicate their CGPA.

Table 1. Demographic data of Treatment and Control class according to race and CGPA

\begin{tabular}{|l|c|c|}
\hline \multirow{2}{*}{\multicolumn{1}{|c|}{ CGPA }} & \multicolumn{2}{c|}{ Class } \\
\cline { 2 - 3 } & Treatment & Control \\
\hline $3.50-4.00$ & 24 & 16 \\
\hline $3.00-3.49$ & 5 & 9 \\
\hline $2.00-2.99$ & 0 & 3 \\
\hline No information & 0 & 6 \\
\hline Total & 29 & 34 \\
\hline
\end{tabular}

The students from the treatment class were taught by the class lecturer using the BLOSSOMS Thermodynamics Energy Conversion video, while the students from control class underwent conventional lecture on Introduction to Thermodynamics. Both lecturers are experienced lecturer in teaching Thermodynamics course and have not attended any active learning training. This study used pre-test and post-test questionnaires to measure the students' achievement in Thermodynamics Energy Conversion topic. A set of pre-test was distributed to each student from both classes before starting the lecture on Introduction to Thermodynamics. The test consists of 14 questions assessing the students' existing knowledge on the current topic. At the end of their class, they were asked to answer the post-test which contain the same questions measuring their development of knowledge after the class. The data were then analysed using SPSS.

\section{Results}

From classroom observation, both lecturers are subject matter experts and know the material well. The lecturers in both classes are comfortable in using teacher centered approaches in their classes. The lecturer in the treatment class was given the BLOSSOMS Thermodynamics video several weeks before the start of the trial and were asked to conduct the topic using the BLOSSOMS video.

Table 2 shows the percentage of the average scores of each pre and post test scores, and the learning gains for control and treatment class. Before undergoing the lecture, the students scored $39.38 \%$ and $47 \%$ in the inventory test for control and treatment class respectively. After the class, they scored $44.69 \%$ and $52.87 \%$ respectively, making the developed knowledge are $5.31 \%$ for control class and $5.87 \%$ for treatment 
class. This indicates that the students in treatment class has developed knowledge slightly higher than the control class.

Table 2. Percentage of pre-test score, post-test score, and learning gain for control class and treatment class

\begin{tabular}{|l|c|c|}
\hline & Control & Treatment \\
\hline Pre-test score (\%) & 39.38 & 47 \\
\hline Post-test score (\%) & 44.69 & 52.87 \\
\hline Learning gain (\%) & 5.31 & 5.87 \\
\hline
\end{tabular}

Table 3 shows the descriptive statistics of the mean score of students' achievement for pre-test and post-test in control and treatment class generated using SPSS software. Higher mean scores in post-test shown in both classes reflects that students have improved their knowledge after the class session, with slightly larger difference seen in treatment class in comparison to control class (Mtreatment=9.52>8.38); (Mcontrol= 8.04>7.09).

Table 3. Mean score and standard deviation for control class and treatment class (analysis of descriptive statistic).

\begin{tabular}{|c|c|c|c|c|}
\hline Class & \multicolumn{2}{|c|}{ Control } & \multicolumn{2}{|c|}{ Treatment } \\
\hline Number of Students (N) & \multicolumn{2}{|c|}{34} & \multicolumn{2}{|c|}{29} \\
\hline Test & Pre & Post & Pre & Post \\
\hline Mean (M) & 7.09 & 8.04 & 8.38 & 9.52 \\
\hline Standard Deviation (SD) & 2.28 & 2.48 & 1.52 & 1.66 \\
\hline
\end{tabular}

Independent sample t-test on students' achievement between treatment class and control class for pre-test score and post-test score are shown in Table 4 and Table 5.

Table 4. Independent sample t-test on students' achievement in inventory pre-test score in control class and treatment class

\begin{tabular}{|l|c|c|c|c|c|c|}
\hline \multicolumn{1}{|c|}{ Class } & N & M & SD & t & df & p \\
\hline Treatment & 29 & 8.38 & 1.522 & 2.594 & 61 & 0.012 \\
\hline Control & 34 & 7.09 & 2.281 & & & \\
\hline
\end{tabular}

Table 5. Independent sample t-test on students' achievement in inventory post-test score in treatment class and control class

\begin{tabular}{|l|c|c|c|c|c|c|}
\hline \multicolumn{1}{|c|}{ Class } & N & M & SD & t & df & p \\
\hline Treatment & 29 & 9.52 & 1.661 & 2.723 & 61 & 0.008 \\
\hline Control & 34 & 8.04 & 2.475 & & & \\
\hline
\end{tabular}

From Table 4, it was found that there was a significant difference in the pre-test scores for treatment class $(\mathrm{M}=8.38, \mathrm{SD}=1.522)$ and control class $(\mathrm{M}=7.09, \mathrm{SD}=$ 2.281 ) conditions $\mathrm{t}(61)=2.594, \mathrm{p}=0.012$. While for post-test score according to Table 5 , there was also significant difference for treatment class $(\mathrm{M}=9.52, \mathrm{SD}=1.67)$ and control class $(\mathrm{M}=8.04, \mathrm{SD}=2.48)$ conditions $\mathrm{t}(61)=2.723, \mathrm{p}=0.008$. The result also 
shows that students in treatment class achieve higher than the students in control class in both pre-test and post-test.

The investigation on the performance is furthered studied based on the paired sample t-test between the control pre and post-test score and treatment pre and post-test score, as shown in Table 6 and 7.

Table 6. Paired sample statistics of pre-test and post-test scores of students in Control class and Treatment class

\begin{tabular}{|l|l|c|c|c|}
\hline \multicolumn{2}{|c|}{} & M & N & SD \\
\hline \multirow{2}{*}{ Pair 1 } & Control_Pre & 7.0882 & 34 & 2.28125 \\
\cline { 2 - 5 } & Control_Post & 8.0441 & 34 & 2.47523 \\
\hline \multirow{2}{*}{ Pair 2 } & Treatment_Pre & 8.3793 & 29 & 1.52160 \\
\cline { 2 - 5 } & Treatment_Post & 9.5172 & 29 & 1.66091 \\
\hline
\end{tabular}

Table 7. Paired sample t-test on pre-test and post-test scores of students in Control class and Treatment class

\begin{tabular}{|l|l|c|c|c|c|c|}
\hline & & M & SD & t & df & p \\
\hline Pair 1 & Control_Pre \& Control_Post & -0.956 & 2.172 & -2.566 & 33 & 0.015 \\
\hline Pair 2 & Treatment_Pre \& Treatment_Post & -1.138 & 1.903 & -3.219 & 28 & 0.003 \\
\hline
\end{tabular}

For control class, it was found that there was a significant difference in the scores for pre-test $(\mathrm{M}=7.09, \mathrm{SD}=2.28)$ and post-test $(\mathrm{M}=8.04, \mathrm{SD}=2.48)$ conditions; $\mathrm{t}(33)=-$ 2.57, $\mathrm{p}=0.015)$. While for treatment class, there was also a significant difference in the scores for pre-test $(\mathrm{M}=8.38, \mathrm{SD}=1.52$ and post-test $(\mathrm{M}=9.52, \mathrm{SD}=1.67)$ conditions; $\mathrm{t}(28)=-3.22, \mathrm{p}=0.003)$.

These results suggest that the students' achievements in inventory test score has increase with BLOSSOMS video. However, the students' achievements in inventory test score has also increase even without using the video.

Table 8. Independent sample t-test on the individual gain of students in control class and

\begin{tabular}{|l|c|c|c|c|c|c|}
\hline \multicolumn{1}{|c|}{ Class } & N & M & SD & t & df & p \\
\hline Treatment & 29 & 1.14 & 1.9 & 0.351 & 61 & 0.727 \\
\hline Control & 34 & 0.96 & 2.17 & & & \\
\hline
\end{tabular}

An independent sample t-test was conducted to compare the individual gain of students in control class and treatment class. It was found that there was no significant difference in the individual gain for treatment class $(\mathrm{M}=1.14, \mathrm{SD}=1.9)$ and control class $(\mathrm{M}=0.96, \mathrm{SD}=2.17)$ conditions; $\mathrm{t}(61)=0.351, \mathrm{p}=0.727)$.

The result suggests that the BLOSSOMS Thermodynamics video does not have a significant effect on the individual gain of the inventory test among students. Specifically, the results suggest that the students' achievement in Thermodynamics Energy Conversion in Generating Electricity does not increase significantly by undergoing learning from the class that used the video. 


\section{Discussion}

The effectiveness of utilizing the Thermodynamics BLOSSOMS video in the Introduction to Thermodynamics can be perceived through the percentage of learning gain, mean scores and t-test results on the students' performance as measured through the energy conversion inventory test score. The results were summarized as follows:

1. The learning gain percentage in the treatment class is slightly higher than the control class.

2. The mean scores of students in treatment class and control class have increased after their class session. Slightly higher results were found in treatment class compared to control class.

3. The independent sample t-test result in pre-test in control and treatment classes was found significant. It was also significant in post-test in both classes.

4. Paired sample t-test between the control class' pre and post-test score and treatment class' pre and post-test score also showed significant results.

5. The independent sample t-test on the learning gain of control and treatment classes showed no significant result.

These results demonstrate that students from both the control and treatment classes improved their knowledge after learning the topic. Students in treatment class scored slightly higher in the post-test than the control class, but they had also scored slightly higher in the pre-test. These results show that at the end of the class, the treatment group have a better understanding of the Introduction to Thermodynamics topic, which could also be influenced by the higher percentage of high achieving students in the treatment class compared to the control class.

Based on the results of independent sample t-test on the learning gain, there was no significant difference in the scores for treatment class and control class. This indicates that the video does not have a significant effect on the individual learning gain of the inventory test among students. Thus, the students' achievement in Thermodynamics Energy Conversion does not increase significantly by the utilization of the video. This is in contrast to an earlier study conducted where there was a significant difference in the individual gain (previously named as score incremental) of students in the treatment and control classes. This could be due to the difference in the skills to conduct active learning of the lecturer in this study compared to the lecturer in the previous study. In the previous study, the class was taught using the same Thermodynamics BLOSSOMS video by a lecturer who had been trained in active learning, resulting in a significant learning gain compared to the students in the control class. The lecturer in the previous study was observed to engage students in the activities guided in the video and were able to conduct the activities well. However, the lecturer in this study was observed to be awkward in conducting the activities given in the video, and were unable to engage many of the students in the active learning sessions.

Thus, even though the Thermodynamics BLOSSOMS video can assist in teaching and learning of the class, the lecturer conducting the class must have the skills for conducting active learning for it to be impactful. Active learning techniques can help 
students to engage in learning by actively participating in the learning process through brainstorming, sharing, reflecting, thinking, etc, rather than listening to lecture. It is well known that students learn and retain more as they become more engaged to the lesson. This is where the instructor plays important role in conducting the activities to engage students in classroom.

\section{Conclusion}

Utilizing BLOSSOMS Thermodynamics Energy Conversion video could increase the students' performance in learning Introduction to Thermodynamics topic when implemented with active learning techniques [9]. This study shows that using the BLOSSOMS video without the implementation of active learning activities could also enhance students' performance in Thermodynamics Energy Conversion topic. As it could not be proven that the video has effect on the individual gain on the topic, thus, it can be concluded that the students' achievement in Thermodynamics Energy Conversion in Generating Electricity does not increase by the utilization of BLOSSOMS video without the proper implementation of active learning techniques. Even though BLOSSOMS can assist Thermodynamics teaching, the lecturer still need skills for conducting active learning for it to be impactful. The utilization of the video could be more effective if the instructor is well-trained in active learning techniques.

\section{Acknowledgement}

The authors acknowledged the Ministry of Higher Education Malaysia and Universiti Teknologi Malaysia for the approved fund under grant number R.J130000.7809.5 F112 that makes this research viable.

\section{$7 \quad$ References}

[1] N. Mulop, K. Mohd, and Z. Tasir, "A Review on Enhancing the Teaching and Learning of Thermodynamics,” Procedia - Soc. Behav. Sci., vol. 56, pp. 703-712, 2012. https://doi.org/ $\underline{10.1016 / j . s b s p r o .2012 .09 .706}$

[2] M. P. Sharma, E. Anderson, and R. Taraban, "Application of Active Learning Techniques to Computer-Based Instruction of Introductory Thermodynamics 1," in Proceedings of the 2002 American Society for Engineering Education Annual Conference \& Exposition, 2002.

[3] S. Hall, C. T. Amelink, and S. S. Conn, "A Case Study of a Thermodynamics Course : Informing Online Course Design,” J. Online Eng. Educ., vol. 1, no. 2, 2010.

[4] F. H. Reardon, "Developing Problem-Solving Skills in Thermodynamics Courses," in Proceedings of the 2001 American Society for Engineering Annual Conference \& Exposition, 2001, no. 1.

[5] K. Mohd Yusof, J. Harun, and M. S. Abu, "Promoting Active Learning in Universiti Teknologi Malaysia," in Conference on Engineering Education 2004, Kuala Lumpur , 1415 Dec 2004, 2004, pp. 14-15. 
[6] R. M. Felder, “Cooperative Learning in Technical Courses: Procedures, Pitfalls, and Payoffs," 1994.

[7] M. Y. Khairiyah and H. Mimi Haryani, "Cooperative learning in process dynamics and control course for undergraduate chemical engineering students," in Proc. 7th Triennial AEESEAP Conf. on Engineering Education, 2003, pp. 115-121.

[8] R. R. Hake, "Interactive-engagement versus traditional methods : A six-thousand-student survey of mechanics test data for introductory physics courses," Am. J. Phys., vol. 66, no. 1, p. 64, 1998. https://doi.org/10.1119/1.18809

[9] W. A. I. Wan Mohd Zawawi, U. S. Radzali, N. F. Jumari, K. Mohd-Yusof, M. F. Daud, and A. A. Mustaffa, "Impact of Blended Learning Open Source Science or Math Studies Interactive Video in the Learning of First Law of Thermodynamics," Chem. Eng. Trans., vol. 56, pp. 985-990, 2017. https://doi.org/10.1109/weef.2017.8467102

[10] Massachusetts Institute of Technology, "MIT BLOSSOMS; Maths \& Science Video Lessons for High School Classes," 2007. [Online]. Available: https://blossoms.mit.edu/.

[11] E. Bransford, John D., Ed.; Brown, Ann L., Ed.; Cocking, Rodney R., How People Learn. 2000.

[12] W. A. I. Wan Mohd Zawawi, K. Mohd-Yusof, U. S. Radzali, and N. F. Jumari, "Impact of BLOSSOMS Energy Conversion Video towards Students Learning of the First Law of Thermodynamics," in Proceedings - 2017 7th World Engineering Education Forum, WEEF 2017- In Conjunction with: 7th Regional Conference on Engineering Education and Research in Higher Education 2017, RCEE and RHEd 2017, 1st International STEAM Education Conference, STEAMEC, 2018. https://doi.org/10.1109/weef.2017.8467102

\section{Authors}

Wan Akmal Izzati Wan Mohd Zawawi received her Bachelor of Engineering and Master of Engineering in electrical engineering from Universiti Teknologi Malaysia, Malaysia in 2011 and 2015. In 2015, she joined Centre for Engineering Education, Universiti Teknologi Malaysia as a research officer. Her current research includes student centred learning, video learning, and epistemology.

Khairiyah Mohd Yusof is the founding Director of Centre for Engineering Education, Universiti Teknologi Malaysia. Currently, she is the President for the Society of Engineering Education Malaysia and was a board member representing Asia for the Research in Engineering Education Network from 2012-2017. A practitioner of problem-based learning (PBL), she regularly conducts courses to train and mentor academics, especially those in STEM areas, in effective implementation of student centered learning techniques such as active learning, cooperative learning and PBL. She also holds a position in School Chemical Engineering (SCE), UT, Malaysia.

Nor Azlinda Azmi received her Master of Philosophy in Engineering Education from Universiti Teknologi Malaysia and her Bachelor of Engineering (Mechanical) from Universiti Teknologi PETRONAS. Since 2014, she has been actively involved in various research projects at the Centre for Engineering Education, Universiti Teknologi Malaysia as a research assistant. Her research interests include studentcentered learning, computer programming education, educational psychology, and pedagogical intervention. 
Tengku Nur Zulaikha Tengku Malim Busu works as a research assistant at the Centre of Engineering Education, Universiti Teknologi Malaysia. Specifically, she assists researches and projects at CEE. She is a graduate student majoring in Chemical Engineering at Universiti Teknologi Malaysia. She gained interest in education field related to engineering since her experience in the Cooperative Problem Based Learning as a student and teaching assistant.

Nur Fazirah Jumari received her Bachelor of Engineering and Master of Engineering in Chemical engineering from Universiti Teknologi Malaysia, Malaysia in 2009 and 2014. She pursued PhD in Engineering Education, Universiti Teknologi Malaysia in 2014. Her niche research includes student centred learning, cooperative learning, problem based learning, and metacognition. She is also a faculty in SCE, UT, Malaysia.

Article submitted 2019-09-14. Resubmitted 2019-10-21. Final acceptance 2019-10-29. Final version published as submitted by the authors. 